\title{
Nanomedicine Formulations for Respiratory Infections by Inhalation Delivery: Covid-19 and Beyond
}

\author{
Oron Zachar ${ }^{1 *}$
}

\begin{abstract}
:
For respiratory infections treatment and prevention, we analyze for the first time the possibility of providing a broad range medication based on metallic nanoparticles colloids ( $\mathrm{NpC}$ ) delivery by controlled aerosol inhalation.

(i) Based on in-vitro data, in combination with aerosol deposition characteristics in the respiratory system, we calculate the required effective formulations, dosages and delivery parameters for an aerosol inhalation treatment to achieve an effective inhibitory concentration (IC) in the target airway surface liquid (ASL); (ii) We evaluate the clinical safety of such dosages, by drawing on information from animal testing data and existing regulatory limits in the USA for such nanoparticles aerosol inhalation safety. Altogether, our analysis indicates a wide range of potential safe and effective dosages that can be clinically explored, targeting the upper respiratory and bronchial tree system. Similar NpC dosages can also provide antibacterial effectiveness for prophylactic treatment in intensive care units to lower risk of hospital ventilator-associated pneumonia (VAP).

Our calculations are phenomenological, independent of mechanisms. Yet, we highlight a mechanism of action by which any suitably designed $\mathrm{NpC}$, with nanoparticles sized $2-10 \mathrm{~nm}$ and having a large negative zetapotential, preferentially bind to viruses with predominantly positively-charged spike proteins. These will be ineffective against viruses with predominantly negatively-charged spike proteins. Accordingly, the popular silver metal base for $\mathrm{NpC}$ serves just as construction ingredient and other metal or metal-oxides which can serve to construct the noted nanoparticle properties would be similarly effective.
\end{abstract}

We suggest that inhalation delivery of the proposed antiviral formulations could be applied as a first-line intervention while respiratory infections are primarily localized to the upper respiratory system and bronchial tree.

\section{Introduction}

Whether it is the seasonal flu, a sore throat, or early stage Covid-19 symptoms, presently in the $21^{\text {st }}$ century there is still no early-stage home treatment medication which is easily accessible and available in pharmacies around the world. The impact of this sorry state of medicine amounted to a global disaster under Covid-19. Moreover, even in the absence of novel epidemics, each year the morbidity and economic cost of respiratory infections are huge. The common research tendency in novel pharmaceuticals is for development of sophisticated, expensive, patent protected, highly potent medications for severely ill patients. Yet, when it comes to public health and pandemic prevention, it may be more impactful to develop mild, cheap, and easily accessible early-stage medications, for home treatment, in order prevent deterioration to the severe hospitalized state. From the pitiful present venture point of anti-viral respiratory infections medication, there may be benefit, humbly and open-mindedly, to revisit some neglected potential options for advancement.

For regular home use, though showing some positive effectiveness results in clinical trials, several suggested anti-malarial agents also have significant known drawbacks. These include hydroxychloroquine (HCQ), ivermectin (IVM), azithromycin (AZ) and doxycycline, which were primarily explored in the context of Covid-19. First, these antimalarial drugs are given systemically as oral medication and do not have a targeted inhalation delivery dosage. Therefore, it seems likely that the anti-malarial medications are inhibiting the spread of the SARS-Cov- 2 infection to 
other body organs, but not specifically inhibiting the early-stage infection source in the respiratory system. Second, it is highly unlikely that such medications, associated with potential significant side effects risks, would ever become widely available for common cold/flu home treatment. Hence, there would be a benefit to find a broad range antiviral respiratory system targeting medication, with low risk of side effects and wide availability potential. In this article we will argue that good candidates for such medication can be found in a well-defined formulation of nanoparticle colloids for inhalation delivery.

The antibacterial and antiviral potential of nanoparticle colloids $(\mathrm{NpC})$ has been extensively demonstrated in in-vitro and animal testing [1-6]. Medical anti-microbial applications of NpC for wound care is approved by the FDA. Unfortunately, a senseless and uncontrolled "alternative medicine" practice of silver NpC ingestion led the pharmacological and academic establishment to widely disregard the potential application of metal-based $\mathrm{NpC}$ as antimicrobial agents in contexts other than wound care. In particular, there has been no rigorous analysis of the potential use of inhalation-delivered $\mathrm{NpC}$ for the prevention and/or treatment of respiratory infections.

We analytically substantiate the potential of antimicrobial $\mathrm{NpC}$ formulations, delivered by inhalation, to minimize the aggravation of respiratory system infections. We evaluate both (A) viral respiratory infections (including with SARS-CoV-2, the causative agent of COVID-19), and (B) bacterial infections, particularly ventilatorassociated pneumonia (VAP) in intensive care unit (ICU) patients. Indeed, the most reliable experience concerning the treatment of respiratory infections has been gained in the context ICU-acquired VAP [7]. There are several unique factors to consider for optimal treatment of the lungs. These include aerosol characteristics, breathing patterns, geometrical factors (lung morphology), disease state, pharmacokinetics (including lung clearance and mucus transport). Not only the total pulmonary drug dose, but also the regional deposition distribution of the lung-deposited aerosol is a key factor for the clinical success of an inhalation therapy [8].

Commonly, the pathogenesis of respiratory infections begins mildly in the nasopharynx and/or upper bronchial tree portions of the respiratory system $[9,10]$. Aggravation occurs once the pathogens and associated inflammation migrate to lower portions of the respiratory [11]. Greater risk together with aggravation of the disease state is characterized by increased microbial load in the upper bronchial tree. Hence, a desirable clinical endpoint for the proposed inhaled $\mathrm{NpC}$ treatment is inhibition of microbial load in the upper sections of the bronchial tree, thereby lowering the risk of infection aggravation and spread. Such an endpoint implies treatment when most patients are still at home with mild symptoms.

To the best of our knowledge, no theoretical or clinical research on the medicinal aerosol inhalation of silverbased $\mathrm{NpC}$ has been published. In this article, we intend to lay the groundwork for future clinical evaluations of inhaled NpC by determining: (i) the NpC material composition required for effective antiviral activity; (ii) the effective inhibitory concentration (IC) required in target respiratory tissues; (iii) the dosage required for practical inhalation delivery of metal-based $\mathrm{NpC}$ antiviral and antibacterial formulations, and (iv) the safe dosage range for clinical evaluation.

\section{Conceptual approach}

Guided by the discussion of Hasan and Lange [12], we adapt the principles of antibiotics inhalation delivery in the context of ventilated ICU patients $[7,27]$ to aerosol delivery of antimicrobial doses to non-ventilated patients, as illustrated in Figure 1. In order to calculate the dose delivered externally with an aerosol nebulizer, one needs to take into account the various losses that occur on rout to the target bronchial tree organ and sensitivity to the aerosol properties which determine the fraction actually deposited. As will be elaborated, our dose calculation is derived from the following analytical results:

- Nanoparticles: Unlike antibacterial, the antiviral potency of metal nanoparticle is highly size dependent, with optimal size being in the range of 3-7 nm. Polymer capping agents (PVP, PVA) reduce the antiviral effectiveness of $\mathrm{NpC}$ and better be avoided.

- Inhibitory concentration (IC): For antiviral applications, minimal IC (MIC) is about $10 \mu \mathrm{g} / \mathrm{mL}$ of the nanoparticles needs to be realized in the target airway surface liquid (ASL).

- Tissue deposition fraction (TDF): During oral breathing of $5 \mu \mathrm{m}$ aerosol droplets, $\mathrm{NpC}$ deposit onto the pharynx (30\%), bronchial tree (30\%), and alveoli (25\%). 
- Inhalation timing losses (ITL): inhalation duration is about a third of the breathing cycle. Thus, using a continuous aerosol source, the aerosol uncontrollably cumulates in the oral cavity during $2 / 3$ of the breathing cycle. Hence, we assume only about $50 \%$ of the nebulized substance is actually inhaled.

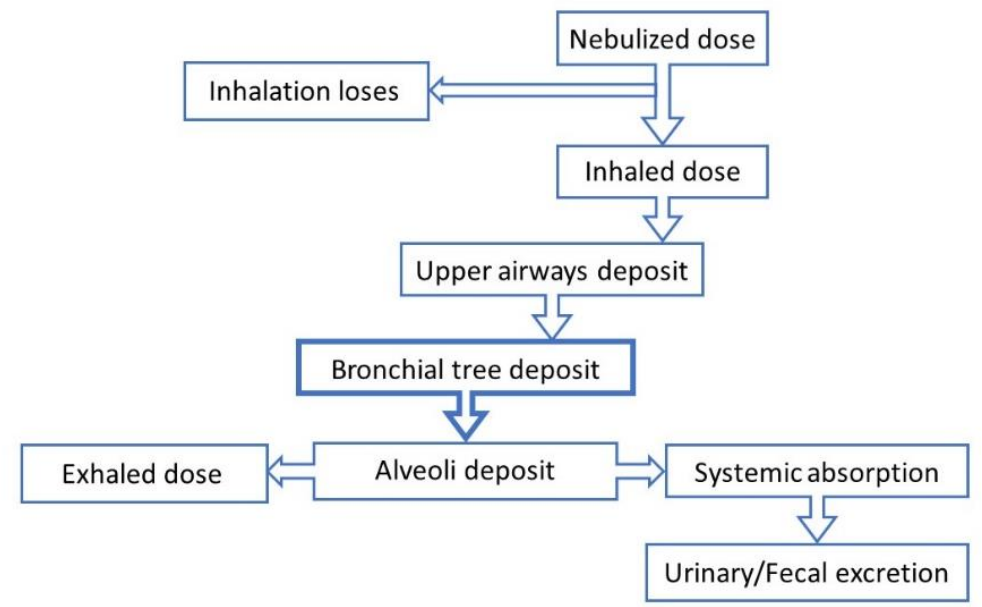

Figure 1: Mechanisms by which the dose of an antimicrobial agent inserted into a nebulizer differs from the dose delivered to the target airway location (based on [7]), with a focus on the fraction deposited in the bronchial tree.

The required delivery dose is calculated by cumulating the effects of each stage between the aerosol produced by the aerosolizing device and final target tissue deposition and dilution into the local airway liquid. Equation 1 delineates the required $\mathrm{NpC}$ aerosolized dose volume (AD) calculation:

$A D=\frac{M V}{T D F \times I T L}\left(\frac{I C}{C C-I C}\right)$

where $A D$ (in $\mathrm{mL}$ ) is a function of the target inhibitory concentration (IC, in $\mu \mathrm{g} / \mathrm{mL}$ ), mucosal volume (MV, in $\mathrm{mL}$ ), tissue deposition fraction (TDF), inhalation time losses fraction (ITL), and colloid concentration (CC, in $\mu \mathrm{g} / \mathrm{mL}$ ).

\section{Results and Analysis}

Table 1 summarizes several possible antiviral formulations delivered by the oral inhalation of aerosol droplets, as calculated from the above Equation-1. Using a common continuous nebulizer (ITL=0.5 assumed) with $5 \mu \mathrm{m}$ droplets size, a nebulized dose of $4 \mathrm{~mL}$ is required to effectively deposit the IC of $40 \mu \mathrm{g} / \mathrm{mL}$ in the bronchial tree. In hospital ICUs, nebulizing $2 \mathrm{ml}$ to $6 \mathrm{~mL}$ of antibiotic drug solution for inhalation delivery is a common practice [13]. Hence, we similarly expect inhalation of $2 \mathrm{ml}$ to $6 \mathrm{~mL}$ nebulized dose to be well-tolerated by home users. We note that, since the total mucosal volume in the alveoli is about ten times greater than that found in the bronchial tree, achieving IC in the alveoli requires a significantly higher dose. For preferential deposited in the alveoli, smaller aerosol droplets of size $3 \mu \mathrm{m}$ are recommended (Table 1).

Table 1. Dose calculations for aerosol droplets of various sizes to treat different target tissues

\begin{tabular}{|c|c|c|c|c|c|c|c|c|}
\hline & Target tissue & $\begin{array}{c}\text { Droplet } \\
\text { size } \\
(\mu \mathrm{m})\end{array}$ & $\begin{array}{c}\text { IC } \\
\text { In target } \\
\text { tissue } \\
(\mu \mathrm{g} / \mathrm{mL})\end{array}$ & $\begin{array}{l}\text { MV } \\
\text { Mucosal } \\
\text { Volume } \\
\text { (mL) }\end{array}$ & $\begin{array}{c}\text { TDF } \\
\text { Tissue } \\
\text { Deposit } \\
\text { Fraction }\end{array}$ & $\begin{array}{c}\text { CC } \\
\text { Colloid } \\
\text { Concentration } \\
(\mu \mathrm{g} / \mathrm{mL})\end{array}$ & $\begin{array}{c}\text { Inhale } \\
\text { d dose } \\
(\mathrm{mL})\end{array}$ & $\begin{array}{c}\text { AD } \\
\text { Aerosolized } \\
\text { Dose } \\
(\mathrm{mL})\end{array}$ \\
\hline (i) & Bronchial tree & 5 & 10 & 1 & 0.25 & 50 & 1 & 2 \\
\hline (ii) & Bronchial tree & 5 & 40 & 1 & 0.25 & 120 & 2 & 4 \\
\hline (iii) & Bronchial tree & 3 & 25 & 1 & 0.1 & 120 & 2.75 & 5.5 \\
\hline (iv) & Alveoli & 3 & 10 & 10 & 0.33 & 120 & 2.75 & 5.5 \\
\hline
\end{tabular}

Based on common practice of established antibiotic inhalation treatments, a practical target IC inhaled antimicrobial dose should be some significant multiple of the theoretical minimum IC (MIC), and may be verified by 
in vivo sampling (e.g., using BAL sampling in ventilated patients). Hence, since the MIC is about $10 \mu \mathrm{g} / \mathrm{mL}$, in practice a recommended treatment dose may be similar to example (ii) in table 1 for targeting the bronchial tree.

\subsection{Target IC Determination for Antiviral Applications}

Antiviral effect is obtained only by nanoparticle sizes of $<10 \mathrm{~nm}$ (see section 3.2 below). The capping molecule used during nanoparticle manufacture to achieve size stabilization affects antiviral potency. The popular PVP cap appears to significantly inhibits antiviral effectiveness. Therefore, in analyzing the published data, we limit our consideration to experiments involving nanoparticles of size $<15 \mathrm{~nm}$ and to non-PVP-stabilized NpC. The evidence summarized in Table 3 indicates that an IC of at least $10 \mu \mathrm{g} / \mathrm{mL}$ is desirable at the target respiratory system location. Our analysis below suggests that the optimal size of silver nanoparticles for antiviral effectiveness is in the range of 3-7 nm, not the $10 \mathrm{~nm}$ diameter used in all the referenced experiments. Hence, there is potential for even better efficacy and/or lower MIC if an optimal NpC diameter is used.

Table 2. Inhibitory concentration (IC) for non-PVP stabilized nanoparticle colloids (NpC) with diameter $\leq 10 \mathrm{~nm}$

\begin{tabular}{|c|c|c|c|}
\hline Virus & $\begin{array}{c}\text { NpC diameter distribution } \\
\text { peak }(\mathrm{nm})\end{array}$ & $\begin{array}{c}\text { IC } \\
(\mu \mathrm{g} / \mathrm{mL})\end{array}$ & Reference \\
\hline Influenza A H3N2 & 9.5 & $<12.5$ & $\lceil 14\rceil$ \\
\hline Monkevpox (MPV) & 10 & $<12.5$ & $\lceil 15\rceil$ \\
\hline Coronavirus TGEV ${ }^{1}$ & 10 & $\sim 10$ & $\lceil 16\rceil$ \\
\hline Tacaribe (TCRV) & 10 & $<10$ & $\lceil 17\rceil$ \\
\hline
\end{tabular}

${ }^{1} \mathrm{TGEV}$, transmissible gastroenteritis virus

\subsection{Relation to the Mechanism of Action}

Our core calculations are phenomenological and thus are not dependent on mechanisms. Yet, an understanding of mechanisms may guide future treatment optimization and alternatives. One should distinguish between the mechanisms of NpC action on bacteria and viruses. There appear to be a multitude of possible ways for bacteria to interact with silver $\mathrm{NpC}$ components (both the nanoparticles and $\mathrm{Ag}^{+}$ions), which have been suggested and discussed by others [18]. On the basis of the broad-range effectiveness of silver NpC with diverse capping surface molecules against many different viruses, we argue that the underlying mechanism of action of $\mathrm{NpC}$ on viruses must be non-specific, simple, and robust. In particular, we argue below that the silver is not important in itself other than as a manufacturing basis for nanoparticles with appropriate physical properties. The prominent material properties of the colloid that affect its antiviral binding action are the nanoparticle size and surface electric zeta potential, with all remaining aspects of the chemical composition being secondary. Hence, other NpC with these properties, such as $\mathrm{NpC}$ based on metal-oxides (e.g., zinc oxides, titanium oxides) would be effective as well (Except that Iron is not recommended, since iron is known to promotes bacterial biofilm growth).

\subsubsection{Antiviral Mechanism of Action - Nanoparticle Size}

The importance of nanoparticle size is much greater for antiviral compared with antibacterial properties. We contend that this is related to the mechanism of action. The antiviral effect arises predominantly from attachment of the nanoparticles themselves to the virus. We posit that there is an essential universality to antiviral effectiveness being limited to nanoparticle sizes of $<10 \mathrm{~nm}$, with this universality arising from the roughly uniform geometric scales of respiratory infection viruses (e.g., influenza and coronavirus): having diameters of about $100 \mathrm{~nm}$, the distance between neighboring spike glycoproteins being $10-20 \mathrm{~nm}$, and the glycoprotein characteristic length being about $15 \mathrm{~nm}$. Thus, based on geometrical limitations alone, for a nanoparticle to interact effectively with a glycoprotein 
site, its diameter must be on the order of $10 \mathrm{~nm}$ or less. Virus functioning becomes disturbed only when the virus is sufficiently covered by attached nanoparticles [19].

We find supporting evidence for the above argument from experiments and direct imaging of nanoparticles binding to human immunodeficiency virus (HIV) [20], whose size is $120 \mathrm{~nm}$, with $22 \mathrm{~nm}$ spacing between the glycoprotein knobs. Interestingly, the observed sizes of nanoparticles bound to HIV (see Figure 2) are exclusively within the range of 1-10 nm, with peak virus attachment effectiveness for nanoparticle sizes in the range of 3-7 nm. No nanoparticles with diameter $>10 \mathrm{~nm}$ were observed to interact with the virus, even though about $40 \%$ of the overall nanoparticle population in the sample was beyond this size range [20].

Consequently, we estimate that experiments in the literature, predominantly performed with larger $\mathrm{NpC}$, have skewed target IC values too high, since their effectiveness arises wholly from the margins of the distribution of particles with sizes $<10 \mathrm{~nm}$. The best we can do, with the presently available, is to focus on analyzing published data only from experiments conducted with $\sim 10 \mathrm{~nm} \mathrm{NpC}$ size. But there is a need to perform experiments with purposefully produced $\mathrm{NpC}$ nanoparticle sizes peak distribution in the range of $3-7 \mathrm{~nm}$.

(a)

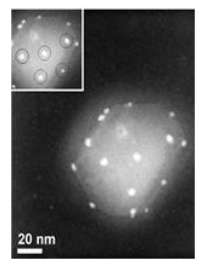

(b)

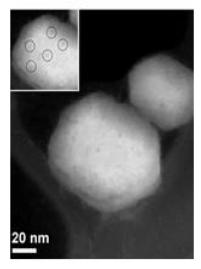

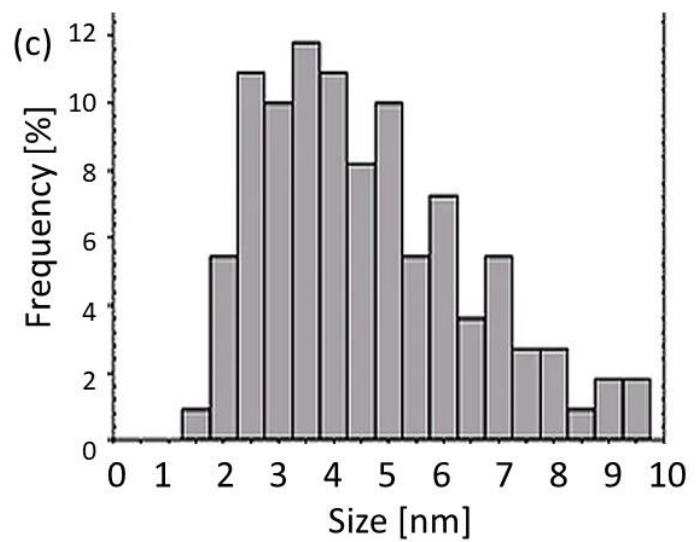

Figure 2. HIV-1 (a) with and (b) without silver nanoparticle treatment. (c) Composite size distribution of silver nanoparticles bound to HIV-1 derived from all tested preparations seems to peak at a nanoparticle size of about $4 \mathrm{~nm}$ (adapted from [20]).

\subsubsection{Antiviral Mechanism of Action -The Electrostatic Potential of Nanoparticles}

Nanoparticles are composites, having a metal core and an envelope capping material (Fig. 3). In a liquid environment, nanoparticles have a surface electric potential, called the zeta potential, the magnitude of which is dependent on solution $\mathrm{pH}$. For a typical silver $\mathrm{NpC}$, the zeta potential is negative.

(A)

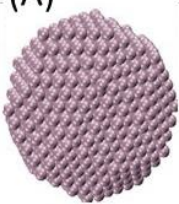

Silver core nanoparticle
poly(Vinyl Alcohol) (PVA)

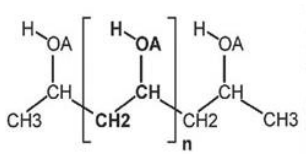

Capping molecule

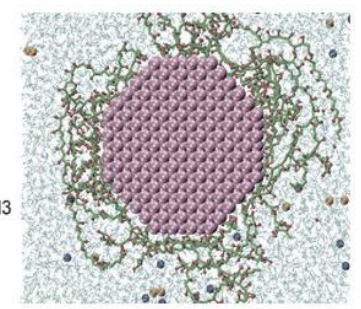

(B)

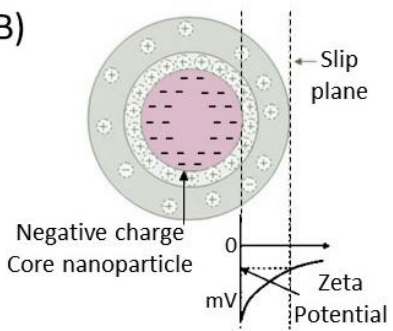

Figure 3. (a) A silver nanocrystal core, the PVA capping, and a full snapshot of an equilibrated PVA-stabilized nanoparticle in aqueous media [21]. (b) The zeta potential of a colloidal nanoparticle is the potential (here negative) at the slip plane surface. 
Unlike bacteria, we conjecture that the broad-range antiviral effectiveness of $\mathrm{NpC}$ is a consequence of the purely electrostatic nature of the interaction. The spike proteins of many human affecting viruses (including influenza and coronaviruses) are positively charged, likely promoting their binding to the predominantly negative surface charge of the host cell receptors (such as ACE2) [22]. Correspondingly, the highly negative surface zetapotential of the nanoparticles (which is required to keep them in colloidal form) leads the nanoparticles to bind selectively to the spike proteins of viruses and thereby neutralize their receptor binding affinity. Hence, nanoparticles with a zeta potential stronger than $-20 \mathrm{mV}$ or $-30 \mathrm{mV}$ are preferred. The silver as a particular atom is unimportant in itself, other than as a manufacturing method for generating a stable, charged, composite nanoparticle colloid. It follows that any colloid of nanoparticles whose size distribution is predominantly in the 2-10 $\mathrm{nm}$ range and that possess a highly negative zeta-potential of strength more than $-20 \mathrm{mV}$ would work as effectively as silver NpC. Correspondingly, we conjecture that viruses whose spike protein binding sites are less positively charged will be less affected by the standard silver $\mathrm{NpC}$ with negative zeta potential.

Generally, the zeta potential becomes more negative with increasing $\mathrm{pH}$. Plotting the range of values for the zeta potential with changing $\mathrm{pH}$ produces a titration curve of $\mathrm{pH}$ vs. zeta potential. Changing $\mathrm{pH}$ may even crosses the zeta potential between negative and positive values. In humans, normal $\mathrm{pH}$ values of tracheal mucus are in the range 6.9-9.0 [23]. Therefore, $\mathbf{~ p C}$ preferably should have a pH of around 7-7.5 in order that their zeta potential not overly degrade in the biological mucosal environment.

\subsection{Coronavirus Evidence}

Transmissible gastroenteritis virus (TGEV), a porcine coronavirus, causes very high mortality in piglets. Figure 4 presents the results of testing the effect of NpC on coronavirus TGEV [16]. With nanoparticles of non-optimal size $10-20 \mathrm{~nm}$ there is a significant effect at a concentration of $12.5 \mu \mathrm{g} / \mathrm{mL}$.

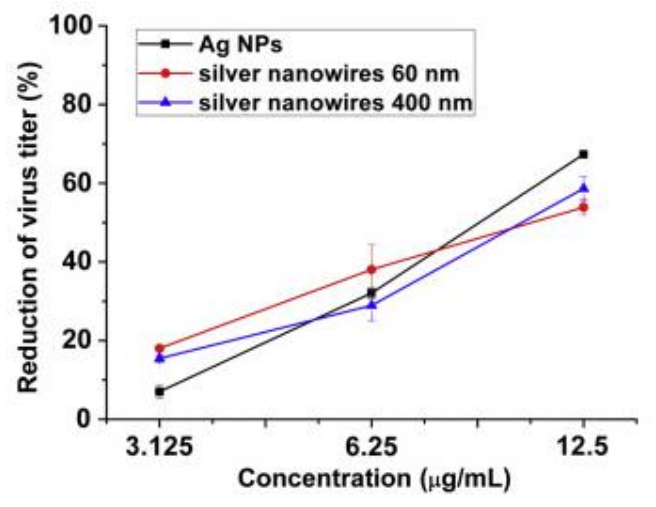

Figure 4. The coronavirus TGEV ( $\mathrm{MOI} 0.5$ ) was incubated with the indicated concentrations of silver-based nanoparticles (AgNP) at $37^{\circ} \mathrm{C}$ for $1 \mathrm{~h}$ in DMEM. The AgNP were of size $<20 \mathrm{~nm}$ (adapted from [16]).

\subsection{Material Properties}

\subsubsection{Distinguishing lonic vs Nanoparticle colloids}

It is important to distinguish between ionic solution (recognized by clear water-like color) and nanoparticle colloids (recognized by a visibly yellow-brownish color). Ionic silver solution consists of positively charged silver ions dissolved in water, whereas silver NpC consist of negatively charged nano-sized chunks of elemental silver, of size 1-100 nm. Both ionic silver and silver NpC manifest antibacterial properties. In contrast, regarding antiviral properties, it has been argued that colloidal particles are about 10 times more potent than ionic silver [24].

\subsubsection{Significance of Selected Stabilization Coating of the Nanoparticles}

There are indications in the literature that the capping agent material can affect antiviral effectiveness. For example, it appears that PVP-capped NpC had practically no antiviral effect on the coronavirus TGEV, whereas a non- 
PVP NpC exhibited strong antiviral effectiveness [16]. A similar result was obtained for HIV, where a ten-fold greater concentration was needed for a PVP-coated NpC sample to achieve the same antiviral effect as a non-PVP NpC [20]. Overall, it appears that a thinner capping layer may have a less deleterious effect on antiviral potency.

\subsection{Anti-bacterial Applications}

For bacterial infections, the literature suggests the presence of a poorly differentiated mixed effect arising from both silver ions and nanoparticles [18]. A major problem in deriving clear numerical conclusions from the published literature is that the IC, commonly stated in weight fraction units $(\mu \mathrm{g} / \mathrm{mL})$, is not taking into account the sensitivity to nanoparticle size. For the same weight fraction $(\mu \mathrm{g} / \mathrm{mL})$, the required IC will be lower for smaller nanoparticles compared with larger nanoparticles (as has been manifested experimentally [25]). This is because for the same weight fraction $(\mu \mathrm{g} / \mathrm{mL})$ the number density $(\mathrm{n} / \mathrm{mL})$ of smaller nanoparticles is higher than larger nanoparticles (nanoparticle number density is proportional to the inverse mass, $1 / \mathrm{m}$, roughly proportional to $1 / \mathrm{R}^{3}$, where $R$ is the nanoparticle diameter). Since higher number density increases the probability of nanoparticle-pathogen interactions, we would expect smaller nanoparticles to exhibit greater antimicrobial effectiveness than larger nanoparticles. Consequently, we proclaim that confusion arises from published studies, using different sized nanoparticles from one another, but expressing the results in weight fraction $\mu \mathrm{g} / \mathrm{mL}$. The variance in the reported outcomes between publications is an artifact of the different nanoparticle sizes used in the various protocols, obscuring the consistency of $\mathrm{NpC}$ effects. Considering the antibacterial properties of silver $\mathrm{NpC}$ against some clinically important bacteria (e.g., Pseudomonas aeruginosa) [25], the typical IC values $(\sim 7 \mu \mathrm{g} / \mathrm{mL}$ ) of small nanoparticles $(\sim 7 \mathrm{~nm})$ are similar to those of the typical antiviral IC, according to our analysis.

\subsection{Dose Calculation}

Antimicrobial drugs exhibit concentration-dependent efficacy. Therefore, ensuring an appropriate concentration in the relevant body fluid is important for obtaining the desired therapeutic action. For inhaled antimicrobials, the relevant body fluid for drug concentration purposes is the airway surface liquid (ASL) [12], also referred to as epithelial lining fluid (ELF). The delivered dose is deposited on and diluted by the ASL. We argue that dosage planning, correction, and controlled verification can all be achieved by focusing on and examining the trachea and/or primary bronchi (G1). Deposition models suggest that the trachea can serve as a good concentration estimator (to within a factor of $3 \mathrm{x}$ ) and effective lower bound for all of the first 10 generations of the bronchial tree (Fig. 5). Therefore, sampling tracheal concentration is a well-defined, and measurable representative of target IC.

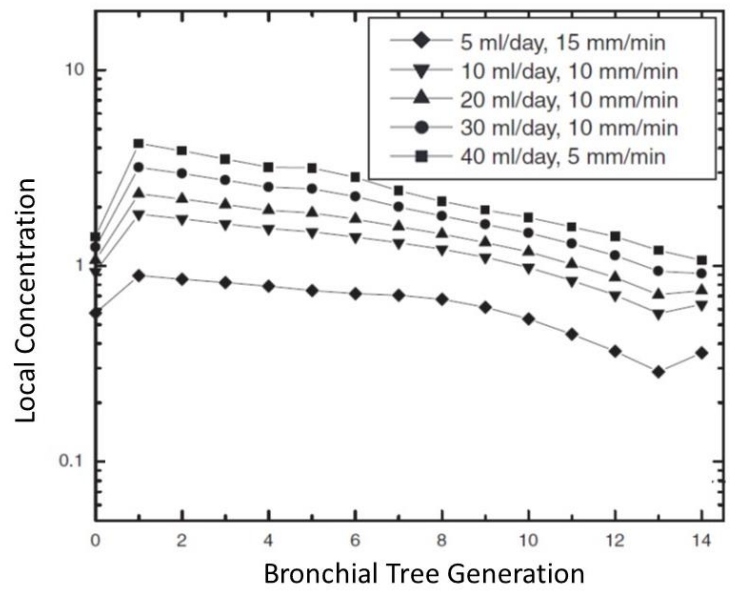

Figure 5: Local concentration of inhaled aerosol in different generations of the bronchial tree, where the trachea is generation 0. Adapted from [12].

Theoretically, calculating the intake dosage that needs to be deposited to achieve the target IC requires knowing the volume of the ASL. However, unlike the predictability of blood volume (for IV delivery), the ASL drug 
concentration resulting from aerosol inhalation deposition has significant inter-personal variability. Such variability may result from individual disease states (e.g., pneumonia, healthy) or lifestyles (e.g., smoking). Verification of the ASL concentration per individual can be achieved from direct measurement of bronchoalveolar lavage (BAL) samples.

\subsubsection{Concentration in Airway Surface Liquid (ASL)}

A dose calculation yields a range of possibilities, rather than a fixed number. Two important concepts are the minimum inhibitory concentration (MIC) and the target IC. In clinical practice, the indicated dosage is expected to be a significant multiple of the MIC within wide clinician-determined margins limited by the bounds of safety. It is common for antibiotics inhalation to target IC that can be ten times (10x) the MIC. Similar considerations may apply for our nanoparticle dose calculation.

The bronchial tree first 10 generations surface area is about $1 \mathrm{~m}^{2}\left(10,000 \mathrm{~cm}^{2}\right)$. The ASL layer thickness ranges from about $6 \mu \mathrm{m}$ in the trachea to $3 \mu \mathrm{m}$ in the $10^{\text {th }}$ generation of the bronchial tree [12]. Thus, we can estimate the combined mucosal volume in the top half of the bronchial tree to be about $1 \mathrm{~mL}$ in a healthy adult. The surface area of the alveoli is about $100 \mathrm{~m}^{2}$, with mucosal thickness of about $0.07 \mu \mathrm{m}$, resulting in a total ASL volume of 7-10 mL. Therefore, disinfection of the upper bronchial tree at early stages, before the infection has spread deep into the lungs, is the most reasonable and realistic target treatment. The disease state significantly affects antimicrobial inhalation delivery. Increased mucus production dilutes the drug concentration in the ASL, compared with healthy adults. Hence, as commonly done with antibiotics inhalation delivery, the preferred practice would be to plan a dose concentration that would be several times the theoretical MIC. Fortunately, for inhalation of $\mathrm{NpC}$ formulations, our theoretically computed MIC is more than 100 times smaller than any estimated safety limit in the regulatory literature. Hence, clinical research of higher doses is possible.

\subsubsection{Deposition Fraction in Target Tissue}

The deposition fraction factor depends on the:

i. Target tissue location: extra-thoracic, trachea-bronchial (TB) tree, or pulmonary (alveoli)

ii. Mode of inhalation: nasal or oral

iii. Size of the aerosol droplets.

As illustrated in the Fig. 6, there is a significant difference in tracheal-bronchial (TB) tree deposition between nasal and oral breathing. Peak nasal breathing TB deposition is only about $10 \%$, whereas oral breathing TB deposition is about $30 \%$. Hence, we recommend oral inhalation.

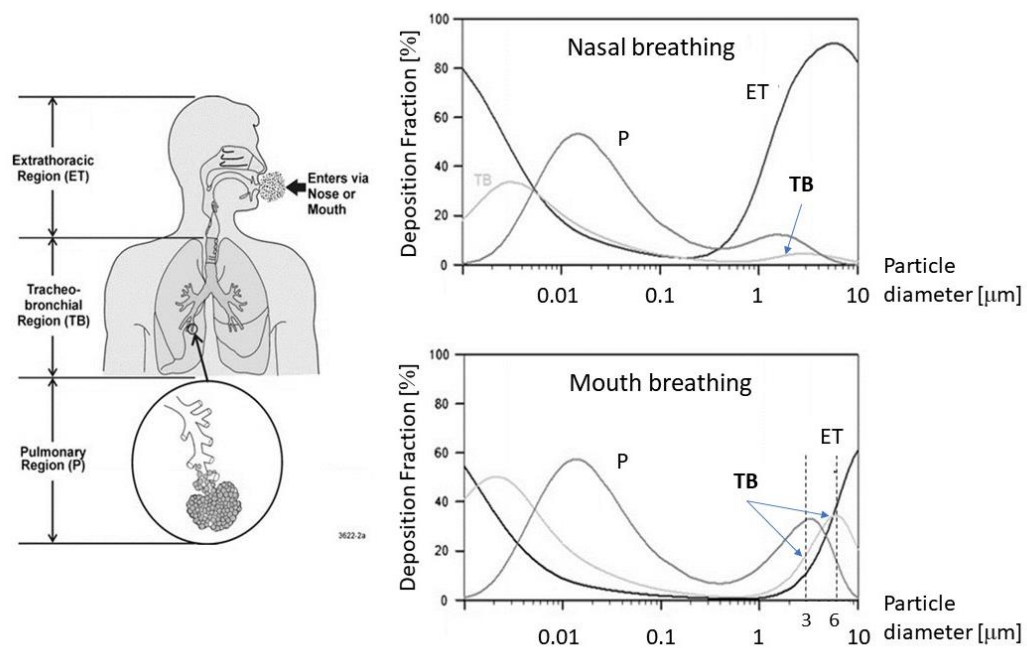

Figure 6. Deposition fractions in primary structures of the respiratory system when breathing at rest. Adapted from [26]. 
Depending on aerosol droplet size, the deposition fraction is different in each tissue region. As illustrated in Fig. 6: (a) the peak bronchial tree deposition fraction (of about 30\%) is obtained with aerosol droplets of diameter $\sim 6 \mu \mathrm{m}$, whereas (b) peak alveoli deposition (of about 30\%) is with aerosol droplets of diameter $\sim 3 \mu \mathrm{m}$. For $5 \mu \mathrm{m}$ droplets, common in mass-produced devices presently on the market, the bronchial tree deposition fraction is $\sim 25 \%$ and alveoli deposition fraction is also $\sim 25 \%$.

\subsubsection{Inhalation Timing Losses}

Inhalation represents only about a third of the duration of a full breathing cycle. Consequently, when aerosols are delivered continuously, during $2 / 3$ of the time the aerosol is cumulated in a cloud within the oral cavity until the next inhalation begins. Hence, we postulate a lower-bound working assumption that only about $50 \%$ of the aerosolized dose is considered to have been effectively inhaled. This would be the common situation for home users utilizing standard commercial medicament aerosol devices available for purchase in pharmacies. By contrast, using a breath-actuated nebulizer (also available commercially) would correspondingly avoid wastage of silver NcP colloid and influence the associated dosage instructions.

\subsubsection{Lung Clearance}

The lungs have innate mechanisms to remove deposited particles. Thus, we need to examine whether the nanoparticles reside long enough in respiratory system surface tissue to fulfil their antiviral potential. For indicative reference, we consider the behavior of inhaled antibiotics (tested in ventilated ICU patients) $[27,28]$. We note that inhalation-deposited antibiotics reside for an effective peak duration of about $2-3 \mathrm{~h}$ in the lungs. The NpC experimental data that we analyzed were commonly for $1 \mathrm{~h}$ treatments (e.g., for the coronavirus presented in Fig. 4). Hence, experience with inhaled antibiotics suggests that the proposed $\mathrm{NpC}$ inhalation will be retained in lung surface tissue for long enough to exhibit antiviral potency.

\subsection{Clinical Safety}

Clinical safety evaluations are performed in the context of an estimated treatment dose and schedule. For the sake of safety analysis, we discuss taking from table-1 example (ii), where $2 \mathrm{~mL}$ of NpC with concentration of $120 \mu \mathrm{g}$ are inhaled, i.e., a dose of $240 \mu \mathrm{g}$ per treatment, taken two times per day, which amounts to a daily deposition of about $480 \mu \mathrm{g}$, taken over a five-day period (similar to an antibiotics regimen).

The human body has mechanisms for the disposal of silver. The natural median daily intake of silver from food and drinks has been reported to be up to $80 \mu \mathrm{g} /$ day [29]. Therefore, our above scenario of a recommended treatment regimen (deposition of about $480 \mu \mathrm{g}$ ) is a significant increase over normal daily dietary intake for a short acute treatment duration of a few days. But what are the safety limits?

When addressing safety and/or toxicity, the professional guidelines distinguish between acute exposure of less than 14 days and prolonged (repeated dose) or chronic exposure of more than 14 days. In our context, only acute ( $<14$ days) exposure is relevant, but we shall discuss both.

USA occupational guidelines and exposure limits for airborne silver dust are all defined on a mass basis. The Occupational Safety and Health Administration (OSHA) adopted the value of the American Conference of Governmental Industrial Hygienists (ACGIH) for a threshold-limit value time-weighted average (TLV-TWA) chronic exposure over a $40-\mathrm{hr}$ week of $100 \mu \mathrm{g} / \mathrm{m}^{3}(0.1 \mu \mathrm{g} / \mathrm{L})$ of metallic silver dust. Under normal breathing of $6-8 \mathrm{~L} / \mathrm{min}$, it corresponds to silver nanoparticle inhalation of $36-42 \mu \mathrm{g} / \mathrm{h}$, for a safe work environment. This equates to daily, 8 hours, inhalation of $\sim 300 \mu \mathrm{g}$ of silver nanoparticles on a routine prolonged basis. Thus, the treatment regimen stipulated here of $240 \mu \mathrm{g}$ dose given two times per day is close to the safety bounds for acceptable chronic intake in the work environment in the USA.

However, chronic work environment exposure is not the appropriate context for acute drug toxicity evaluation. We should focus on evaluation of short-term inhalation. It has been shown that even after 90 days of continuous inhalation exposure to high doses of silver nanoparticles (total of 1,143 $\mu \mathrm{g} /$ day of silver - about three times (3x) our realistic treatment regimen example - the accumulated tissue levels recover to normal within about 12 weeks from 
the end of treatment (Figure 7). This provides a very strong indication of the safety and tolerance of short-term silver $\mathrm{NpC}$ inhalation exposure, in that it does not lead to any lasting accumulation in body tissues.

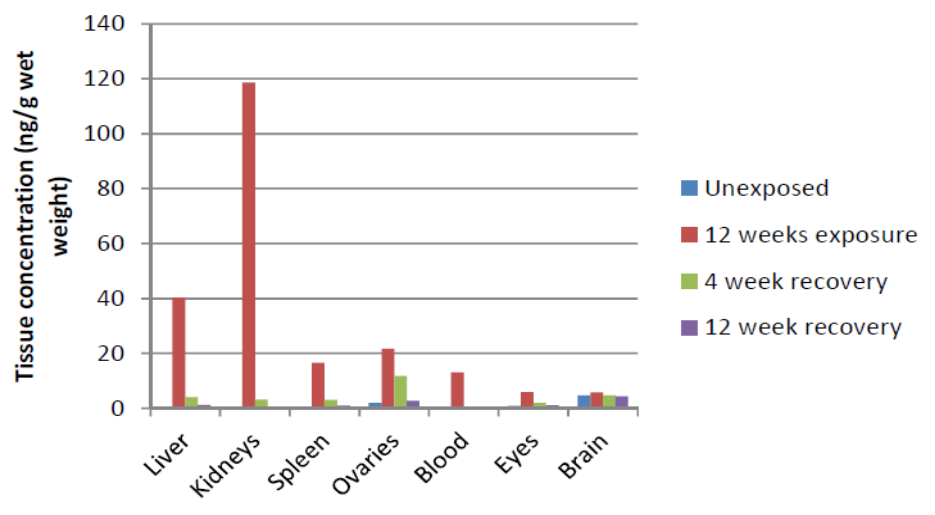

Figure 7. Tissue silver concentrations in female rats exposed to high levels of AgNP $\left(381 \mu \mathrm{g} / \mathrm{m}^{3}\right.$ silver nanoparticles of $\sim 15 \mathrm{~nm}$ diameter, for $6 \mathrm{~h} /$ day, which amounts to an inhalation dosage of 1,143 $\mu \mathrm{g} /$ day of silver) in a 90-day inhalation study, followed by a 12-week recovery period. Adapted from [30,31].

A test closest to our envisioned treatment protocol was performed on rats for 10 days, 4 hours/day, at a concentration of $3,300 \mu \mathrm{g} / \mathrm{m}^{3}(3.3 \mu \mathrm{g} / \mathrm{L})$ using an aerosol of $5 \mathrm{~nm}$ silver nanoparticles, resulting in minimal pulmonary toxicity or inflammation [32]. For a human breathing at a normal rate of $6 \mathrm{~L} / \mathrm{min}$, this translates to a daily inhaled dosage of silver nanoparticle aerosol of $4,700 \mu \mathrm{g} /$ day. This study indicates that, for acute short-term treatment of less than 10 days, even an inhalation intake of $4,000 \mu \mathrm{g} / \mathrm{day}$, which is about 10 times our realistic treatment regimen example, would induce no adverse reaction or a lasting residue.

\section{Discussion}

Though marred by the charlatan claims by unprofessional "alternative medicine" commercial products, there is well-established scientific research on the antibacterial and antiviral properties of silver NpC. Yet, its potential application for the treatment of respiratory infections has never been properly explored. The surveyed literature indicates that silver nanoparticles colloids $(\mathrm{NpC})$ of diameter 3-7 $\mathrm{nm}$ can be highly effective in suppressing many viral pathogens at an inhibitory concentration (IC) of $10 \mu \mathrm{g} / \mathrm{mL}$ (Table 2). However, we obtained these values by making somewhat indirect inferences and therefore more focused research is called for. For the treatment of lung infections via inhalation delivery of silver $\mathrm{NpC}$ (Table 1), to achieve a significant IC of $40 \mu \mathrm{g}$ (i.e., $4 \mathrm{x}$ of MIC) in the bronchial tree airway surface liquid (ASL) would require inhalation of $1 \mathrm{~mL}$ of $\mathrm{NpC}$ at a concentration of $120 \mu \mathrm{g}$. If common market continuous nebulizers are used, one would need to nebulize a dose of twice the amount $240 \mu \mathrm{g}$ (because of $50 \%$ inhalation time losses). For treatment delivered twice daily, this corresponds to a daily deposition of about $240 \mu \mathrm{g}$. The available safety information indicates that such doses and regimens are well within the safe range and enable the safe delivery of even ten times (10x) the IC noted in Table 1 . We estimate that these formulations can be effective for the prevention and treatment of any early-stage respiratory viral infection, including infection with SARS-CoV-2.

To set the scale of potential benefits, we flash out the remarkable results of an Influenza H3N2 in-vivo experiment done on mice by Xiang et al. (one of the very few in vivo animal experiments in the NpC literature), comparing the effectiveness of intranasal administration of $\mathrm{NpC}$ to that of Tamiflu (Oseltamivir) [14]. Tamiflu is claimed to reduce the number of patients who have serious complications from the flu, such as pneumonia (by $44 \%$ ) or hospitalization (by 63\%). A NpC treatment, if as effective as in the mice model, could cost less than $1 / 10$ fraction of Tamiflu, with much less side effect risk, can be available essentially OTC (as the market availability of NpC already is), and easily manufactured locally at any country in the world. As shown in Fig.8 below, it appears that potentially $\mathrm{NpC}$ can be as effective as Tamiflu. But no investment in clinical human trials was ever done to investigate the 
possibility. We can only speculate that this is due to the lack of financial incentives for any conventional pharma company to make the required investment in development and regulatory procedures. One of the main goals of this paper is to motivate and guide the future clinical and regulatory development of $\mathrm{NpC}$ treatment formulations.

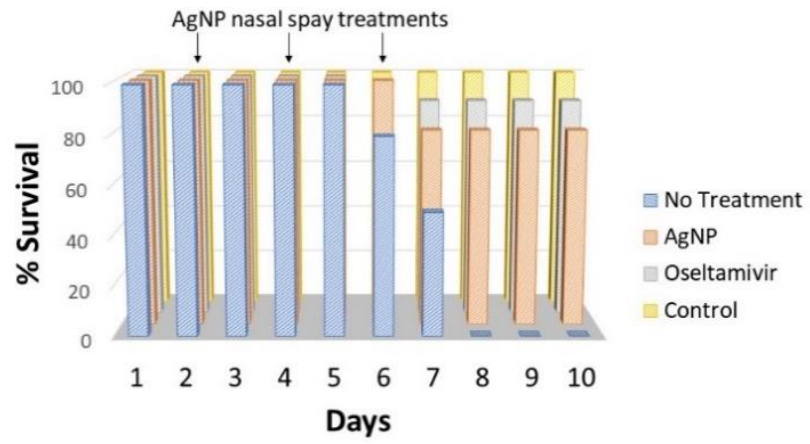

Figure-8: In-vivo intranasal NpC administration protected mice from H3N2 infection. Adapted from [14].

For bacterial infections, particularly in the context of preventing ICU-acquired VAP, the same formulations are expected to be applicable. An additional risk-reduction benefit of silver NpC inhalation treatment for ventilated patients is the possibility of suppression of biofilm formation inside the endotracheal or tracheostomy tube.

1 Yamor Technologies Ltd

* Correspondence: oron@yamor-tech.com

\section{Conflict of interest statement}

Yamor Technologies promotes a drug development program based on the framework presented in this article.

Funding: This research received no external funding.

Acknowledgments: We thank Alex Singer for editorial assistance in the manuscript's preparation.

Consent statement/Ethical approval: Not required.

\section{References}

1. Aderibigbe BA. Metal-based nanoparticles for the treatment of infectious diseases. Molecules [Internet]. 22(8), 1370 (2017). Available from: http://www.mdpi.com/1420-3049/22/8/1370.

2. Nakamura S, Sato M, Sato Y, et al. Synthesis and application of silver nanoparticles (Ag NPs) for the prevention of infection in healthcare workers. Int. J. Mol. Sci. [Internet]. 20(15), 3620 (2019). Available from: https://www.mdpi.com/1422-0067/20/15/3620.

3. Siadati SA, Afzali M, Sayadi M. Could silver nano-particles control the 2019-nCoV virus?; An urgent glance to the past. Chem. Rev. Lett. [Internet]. 3(1), 9-11 (2020). Available from: http://www.chemrevlett.com/article_105425.html.

4. Galdiero S, Falanga A, Vitiello M, Cantisani M, Marra V, Galdiero M. Silver nanoparticles as potential antiviral agents. Molecules [Internet]. 16(10), 8894-8918 (2011). Available from: http://www.mdpi.com/1420-3049/16/10/8894.

5. Balavandy SK, Shameli K, Biak DRBA, Abidin ZZ. Stirring time effect of silver nanoparticles prepared in glutathione mediated by green method. Chem. Cent. J. 8(1), 11 (2014).

6. Haggag E, Elshamy A, Rabeh M, et al. Antiviral potential of green synthesized silver nanoparticles of Lampranthus coccineus and Malephora lutea. Int. J. Nanomedicine [Internet]. Volume 14, 6217-6229 (2019). Available from: 
https://www.dovepress.com/antiviral-potential-of-green-synthesized-silver-nanoparticles-of-lampr-peer-reviewedarticle-IJN.

7. Rouby JJ, Bouhemad B, Monsel A, Brisson H, Arbelot C, Lu Q. Aerosolized antibiotics for ventilator-associated pneumonia: Lessons from experimental studies. Anesthesiology. 117(6), 1364-1380 (2012).

8. Darquenne C, Fleming JS, Katz I, et al. Bridging the gap between science and clinical efficacy: Physiology, imaging, and modeling of aerosols in the lung. J. Aerosol Med. Pulm. Drug Deliv. 29(2), 107-126 (2016).

9. Behrens G, Stoll M. Pathogenesis and immunology [Internet]. In: Influenza Report. Kamps BS, Hoffmann C, Preiser W (Eds.), Flying Publisher, Paris, France, 92-109 (2006) [cited 2020 Nov 30]. Available from:

http://www.influenzareport.com/ir/pathogen.htm.

10. Garland JS. Ventilator-associated pneumonia in neonates: An update. Neoreviews [Internet]. 15(6), e225-e235 (2014). Available from: https://neoreviews.aappublications.org/content/15/6/e225.

11. Manjarrez-Zavala EM, Patricia D, Horacio L, Ocadiz-Delgado R, Cabello-Gutierrez C. Pathogenesis of viral respiratory infection [Internet]. In: Respiratory Disease and Infection - A New Insight. Mahboub BH (Ed.), InTech (2013) [cited 2020 Nov 30]. Available from: http://dx.doi.org/10.5772/54287.

12. Hasan MA, Lange CF. Estimating in vivo airway surface liquid concentration in trials of inhaled antibiotics. J. Aerosol Med. 20(3), 282-293 (2007).

13. Dugernier J, Reychler G, Wittebole X, et al. Aerosol delivery with two ventilation modes during mechanical ventilation: a randomized study. Ann. Intensive Care. 6(1), 73 (2016).

14. Xiang D, Zheng C, Zheng $Y$, et al. Inhibition of A/Human/Hubei/3/2005 (H3N2) influenza virus infection by silver nanoparticles in vitro and in vivo. Int. J. Nanomedicine [Internet]. 8(1), 4103 (2013). Available from: http://dx.doi.org/10.2147/IJN.S53622.

15. Rogers J V., Parkinson C V., Choi YW, Speshock JL, Hussain SM. A preliminary assessment of silver nanoparticle inhibition of Monkeypox virus plaque formation. Nanoscale Res. Lett. 3(4), 129-133 (2008).

16. Lv X, Wang P, Bai R, et al. Inhibitory effect of silver nanomaterials on transmissible virus-induced host cell infections. Biomaterials. 35(13), 4195-4203 (2014).

17. Speshock JL, Murdock RC, Braydich-Stolle LK, Schrand AM, Hussain SM. Interaction of silver nanoparticles with Tacaribe virus. J. Nanobiotechnology. 8(1), 19 (2010).

18. Dakal TC, Kumar A, Majumdar RS, Yadav V. Mechanistic basis of antimicrobial actions of silver nanoparticles. Front. Microbiol. 7(Nov), 1831 (2016).

19. Morris D, Ansar M, Speshock J, et al. Antiviral and immunomodulatory activity of silver nanoparticles in experimental rsv infection. Viruses [Internet]. 11(8) (2019). Available from: https://pubmed.ncbi.nIm.nih.gov/31398832/.

20. Elechiguerra JL, Burt JL, Morones JR, et al. Interaction of silver nanoparticles with HIV-1. J. Nanobiotechnology [Internet]. 3(1), 6 (2005). Available from: http://jnanobiotechnology.biomedcentral.com/articles/10.1186/1477-31553-6.

21. Kyrychenko A, Pasko DA, Kalugin ON. Poly(vinyl alcohol) as a water protecting agent for silver nanoparticles: The role of polymer size and structure. Phys. Chem. Chem. Phys. 19(13), 8742-8756 (2017).

22. Prabakaran P, Xiao X, Dimitrov DS. A model of the ACE2 structure and function as a SARS-CoV receptor. Biochem. Biophys. Res. Commun. 314(1), 235-241 (2004).

23. Clary-Meinesz C, Mouroux J, Cosson J, Huitorel P, Blaive B. Influence of external pH on ciliary beat frequency in human 
bronchi and bronchioles. Eur. Respir. J. 11(2), 330-333 (1998).

24. Lara HH, Ayala-Nuñez N V., Ixtepan-Turrent L, Rodriguez-Padilla C. Mode of antiviral action of silver nanoparticles against HIV-1. J. Nanobiotechnology [Internet]. 8(1), 1 (2010). Available from:

http://jnanobiotechnology.biomedcentral.com/articles/10.1186/1477-3155-8-1.

25. Martínez-Castañón GA, Niño-Martínez N, Martínez-Gutierrez F, Martínez-Mendoza JR, Ruiz F. Synthesis and antibacterial activity of silver nanoparticles with different sizes. J. Nanoparticle Res. [Internet]. 10(8), 1343-1348 (2008). Available from: https://link.springer.com/article/10.1007/s11051-008-9428-6.

26. Cheng YS. Mechanisms of pharmaceutical aerosol deposition in the respiratory tract. AAPS PharmSciTech [Internet]. 15(3), 630-640 (2014). Available from: https://link.springer.com/article/10.1208/s12249-014-0092-0.

27. Dhanani J, Fraser JF, Chan HK, Rello J, Cohen J, Roberts JA. Fundamentals of aerosol therapy in critical care. Crit. Care. 20(1), 1-16 (2016).

28. Lu Q, Girardi C, Zhang M, et al. Nebulized and intravenous colistin in experimental pneumonia caused by Pseudomonas aeruginosa. Intensive Care Med. 36(7), 1147-1155 (2010).

29. WHO. Silver in drinking-water: Background document for development of WHO Guidelines for Drinking-water Quality [Internet]. Geneva. Available from: https://www.who.int/water_sanitation_health/dwq/chemicals/silver.pdf.

30. Fewtrell L. Silver: Water disinfection and toxicity [Internet]. . Available from:

https://www.who.int/water_sanitation_health/dwq/chemicals/Silver_water_disinfection_toxicity_2014V2.pdf.

31. Song KS, Sung JH, Ji JH, et al. Recovery from silver-nanoparticle-exposure-induced lung inflammation and lung function changes in Sprague Dawley rats. Nanotoxicology. 7(2), 169-180 (2013).

32. Stebounova L V., Adamcakova-Dodd A, Kim JS, et al. Nanosilver induces minimal lung toxicity or inflammation in a subacute murine inhalation model. Part. Fibre Toxicol. 8(1), 5 (2011). 